\title{
Analysis of cat oocyte activation methods for the generation of feline disease models by nuclear transfer Chunmin Wang1, William F Swanson ${ }^{2}$, Jason R Herrick ${ }^{2,3}$, Kiho Lee ${ }^{1}$ and Zoltan Machaty*1
}

Address: ${ }^{1}$ Department of Animal Sciences, Purdue University, West Lafayette, IN 47907, USA, ${ }^{2}$ Center for Conservation and Research of Endangered Wildlife, Cincinnati Zoo and Botanical Garden, Cincinnati, OH 45220, USA and ${ }^{3}$ College of Veterinary Medicine, University of Illinois at Urbana-Champaign, Urbana, IL 61802, USA

Email: Chunmin Wang - wang192@purdue.edu; William F Swanson - bill.swanson@cincinnatizoo.org; Jason R Herrick - jherrick@illinois.edu; Kiho Lee-lee308@purdue.edu; Zoltan Machaty* - zmachaty@purdue.edu

* Corresponding author

Published: II December 2009

Reproductive Biology and Endocrinology 2009, 7:148 doi:10.1 186/1477-7827-7-148

This article is available from: http://www.rbej.com/content/7/I/I 48

(c) 2009 Wang et al; licensee BioMed Central Ltd.

This is an Open Access article distributed under the terms of the Creative Commons Attribution License (http://creativecommons.org/licenses/by/2.0), which permits unrestricted use, distribution, and reproduction in any medium, provided the original work is properly cited.

\begin{abstract}
Background: Somatic cell nuclear transfer in cats offers a useful tool for the generation of valuable research models. However, low birth rates after nuclear transfer hamper exploitation of the full potential of the technology. Poor embryo development after activation of the reconstructed oocytes seems to be responsible, at least in part, for the low efficiency. The objective of this study was to characterize the response of cat oocytes to various stimuli in order to fine-tune existing and possibly develop new activation methods for the generation of cat disease models by somatic cell nuclear transfer.
\end{abstract}

Methods: First, changes in the intracellular free calcium concentration [Ca2+]i in the oocytes induced by a number of artificial stimuli were characterized. The stimuli included electroporation, ethanol, ionomycin, thimerosal, strontium-chloride and sodium $(\mathrm{Na}+)$-free medium. The potential of the most promising treatments (with or without subsequent incubation in the presence of cycloheximide and cytochalasin B) to stimulate oocyte activation and support development of the resultant parthenogenetic embryos was then evaluated. Finally, the most effective methods were selected to activate oocytes reconstructed during nuclear transfer with fibroblasts from mucopolysaccharidosis I- and alpha-mannosidosis-affected cats.

Results: All treatments were able to elicit a $[\mathrm{Ca} 2+] \mathrm{i}$ elevation in the ooplasm with various characteristics. Pronuclear formation and development up to the blastocyst stage was most efficiently triggered by electroporation $(60.5+/-2.9$ and $11.5+/-1.7 \%)$ and the combined thimerosal/DTT treatment $(67.7+/-1.8$ and $10.6+/-1.9 \%)$; incubation of the stimulated oocytes with cycloheximide and cytochalasin $B$ had a positive effect on embryo development. When these two methods were used to activate oocytes reconstructed during nuclear transfer, up to $84.9 \%$ of the reconstructed oocytes cleaved. When the 2 to 4 -cell embryos (a total of 220) were transferred into 19 recipient females, 4 animals became pregnant. All of the fetuses developed from oocytes activated by electroporation followed by cycloheximide and cytochalasin B incubation; no fetal development was detected as a result of thimerosal/DTT activation. Although heartbeats were detected in two of the cloned fetuses, no term development occurred. 
Conclusion: Electroporation proved to be the most effective method for the activation of cat oocytes reconstructed by nuclear transfer. The combined thimerosal/DTT treatment followed by cycloheximide and cytochalasin B incubation triggered development effectively to the blastocyst stage; whether it is a viable option to stimulate term development of cloned cat embryos needs further investigations.

\section{Background}

Ovulated mammalian oocytes are arrested at the metaphase stage of their second meiotic division [1]. Normally, they resume meiosis and enter the first interphase at the time of fertilization when the fertilizing sperm activates the oocyte's developmental program by triggering changes in its intracellular free calcium concentration $\left[\mathrm{Ca}^{2+}\right]_{i}$. Changes in the $\left[\mathrm{Ca}^{2+}\right]_{i}$ can also be induced artificially and as a result parthenogenetic oocyte activation can take place. Although mammalian parthenogenetic embryos never develop to term, a great number of invertebrate and vertebrate animal species are able to reproduce via parthenogenesis [2].

During parthenogenetic activation, the increase in the $\left[\mathrm{Ca}^{2+}\right]_{\mathrm{i}}$ must be able to trigger the numerous biological events that are associated with fertilization [3]. The process is an integral part of several assisted reproductive technologies and has particular relevance in somatic cell nuclear transfer [4]. Numerous oocyte activation methods have been designed to mimic the $\mathrm{Ca}^{2+}$ signal induced by the sperm; however, very few of them are able to generate the oscillatory $\mathrm{Ca}^{2+}$ signal seen during mammalian fertilization. Thus in most cases a single $\left[\mathrm{Ca}^{2+}\right]_{\mathrm{i}}$ rise is induced to stimulate development of the reconstructed oocyte [5]. Although this was shown capable of triggering oocyte activation [6], the amplitude, frequency and duration of repetitive $\mathrm{Ca}^{2+}$ signals are believed to have profound effects not only on the immediate events of oocyte activation but also on peri-implantation development [7].

Activation of oocytes of many domestic species including the domestic cat has been described and used in reproductive research [8]. Cats are useful research models for a number of reasons. They are valuable for the study of hereditary diseases in humans since they can provide insight into disease etiology and pathology [9-13]. Cat models also facilitate investigation of promising treatments including gene therapies, as recently shown for the lysosomal storage diseases mucopolysaccaridosis (MPS) and $\alpha$-mannosidosis (AMD); [14,15]. Reproductive research on domestic cats is also important for conserving endangered felid species [16-18]. Somatic cells isolated from nondomestic felids can be transferred into enucleated domestic cat oocytes, and it has been demonstrated that this nuclear transfer approach has the potential of generating live offspring if the two felid populations are not too distantly related [19]. Despite the occasional successes low birth rates after nuclear transfer, just like in most other species, remain a formidable challenge. One potential reason for the low efficiency is poor embryo development following activation of the reconstructed oocytes. The number of methods known to induce parthenogenetic development of cat oocytes is rather low; the published methods are limited to electroporation, ethanol and the ionophore A23187 [8,19]. In most cases activation techniques developed for other species have been adopted for producing the cloned cat embryos; this may limit embryonic development after embryo transfer. The aims of this study were to 1 ) characterize $\left[\mathrm{Ca}^{2+}\right]_{\mathrm{i}}$ changes in cat oocytes induced by different stimuli; 2) develop new activation methods that could be applied after nuclear transfer to produce cleavage-stage embryos; and 3) assess the feasibility of nuclear transfer to produce cloned cats affected with the lysosomal storage diseases MPS or AMD.

\section{Methods}

All chemicals were purchased from Sigma-Aldrich Chemical Company (St. Louis, MO, U.S.A.) unless otherwise indicated. Experiments were conducted according to guidelines approved by the Institutional Animal Care and Use Committee (IACUC) at the Cincinnati Zoo \& Botanical Garden.

\section{In vitro oocyte maturation}

Cat ovaries were collected after routine ovariectomy. Cumulus-oocytes complexes (COCs) were collected by slicing in Hepes-buffered Tyrode's Lactate (TL-Hepes) medium and matured in groups of 10 in 100- $\mu$ l drops of Feline Optimized Culture Medium (FOCM; [20]) supplemented with $0.1 \mathrm{mM}$ cysteamine, $0.6 \mathrm{mM}$ cysteine, vitamins $(1 \times$ MEM), ITS $(1 \times)$, glucose (up to a total of $6 \mathrm{mM}$ ), $1.0 \mathrm{IU} / \mathrm{ml}$ equine chorionic gonadotropin (eCG), $2.0 \mathrm{IU} /$ $\mathrm{ml}$ human chrorionic gonadotropin (hCG), $25 \mathrm{ng} / \mathrm{ml}$ epidermal growth factor (EGF) and $4 \mathrm{mg} / \mathrm{ml}$ bovine serum albumin (BSA), for $24 \mathrm{~h}$. The cumulus cells were then removed using $0.3 \mathrm{mg} / \mathrm{ml}$ hyaluronidase.

\section{$\mathrm{Ca}^{2+}$ imaging and fluorescence measurements}

Mature oocytes were loaded with the $\mathrm{Ca}^{2+}$ indicator dye fura- 2 by incubation in the presence of $2 \mu \mathrm{M}$ fura- $2 \mathrm{AM}$ (acetoxymethyl ester form) and $0.02 \%$ detergent pluronic F-127 (Invitrogen; Carlsbad, CA, U.S.A.) for 45 min. The 
oocytes were then rinsed and transferred to a chamber with a glass coverslip as the bottom. They were exposed to various treatments and changes in the $\left[\mathrm{Ca}^{2+}\right]_{\mathrm{i}}$ were recorded using InCyt Im2, a dual-wavelength fluorescence imaging system (Intracellular Imaging, Inc.; Cincinnati, $\mathrm{OH}$, U.S.A.). Fluorescence was recorded by calculating the ratio of fura- 2 fluorescence at $510 \mathrm{~nm}$ excited by UV light alternatively at 340 and $380 \mathrm{~nm}$. The $\mathrm{Ca}^{2+}$ concentration was calculated by comparing the ratio of fluorescence at 340 and $380 \mathrm{~nm}$ against a standard curve of known $\mathrm{Ca}^{2+}$ concentration prepared with fura-2 potassium salt (Invitrogen). During measurements, the baseline $\left[\mathrm{Ca}^{2+}\right]_{i}$ was detected first and then different stimuli were applied. For each treatment, the fluorescence measurement was performed for at least $10 \mathrm{~min}$ and then it was repeated several times using different oocytes.

\section{Oocyte treatments}

A number of stimuli were tested for their ability to trigger an elevation in the $\left[\mathrm{Ca}^{2+}\right]_{\mathrm{i}}$ of the oocytes. Then, based on the results of these measurements and on data published in other species, a number of treatments were identified that were deemed to have the potential to trigger parthenogenetic development of the oocytes. The oocytes were treated using the selected methods, then a portion of them were incubated in the presence of $10 \mu \mathrm{g} / \mathrm{ml}$ cycloheximide (a protein synthesis blocker) and $7.5 \mu \mathrm{g} / \mathrm{ml}$ cytochalasin $\mathrm{B}$ (an inhibitor of actin polymerization) for $4 \mathrm{~h}$ prior to culture; the rest of the oocytes were cultured without inhibitor supplementation. In previous studies the use of such inhibitors had a positive effect on embryo development following oocyte activation (for review see [21]. The oocytes were then cultured as described below and embryonic development induced by the different methods was monitored. The following treatments were tested.

\section{Electric DC pulse}

Individual oocytes were transferred to a chamber with two stainless steel electrodes where the bottom of the chamber had been replaced with a glass coverslip. The chamber was filled with electroporation medium (consisting of mannitol $0.3 \mathrm{M}, \mathrm{CaCl}_{2} 0.1 \mathrm{mM}, \mathrm{MgSO}_{4} 0.1 \mathrm{mM}$, HEPES $0.5 \mathrm{mM}$ and BSA $0.01 \mathrm{mg} / \mathrm{ml}$ ) and placed on the stage of an inverted microscope. After a 5-min equilibration period the steady-state $\mathrm{Ca}^{2+}$ levels were measured, then two DC pulses of various characteristics $(1.0 \mathrm{kV} / \mathrm{cm}$ for $20 \mu \mathrm{sec}$; $1.2 \mathrm{kV} / \mathrm{cm}$ for $60 \mu \mathrm{sec}$; or $2 \mathrm{kV} / \mathrm{cm}$ for $60 \mu \mathrm{sec}), 1 \mathrm{sec}$ apart, were applied to the oocytes [21] and changes in the $\left[\mathrm{Ca}^{2+}\right]_{\mathrm{i}}$ were monitored. To stimulate development two DC pulses of either $1.0 \mathrm{kV} / \mathrm{cm}$ for $20 \mu \mathrm{sec}$ or $1.2 \mathrm{kV} / \mathrm{cm}$ for 60 $\mu$ sec were applied.

\section{Ethanol}

Oocytes were placed into the $\mathrm{Ca}^{2+}$ measurement chamber containing TL-Hepes and ethanol (200 proof) was added to the medium to obtain $7 \%(\mathrm{v} / \mathrm{v})$ final ethanol concentration [22]. Changes in the $\left[\mathrm{Ca}^{2+}\right]_{i}$ were recorded by the fluorescence imaging system. In order to trigger parthenogenetic development, oocytes were exposed to $7 \%(\mathrm{v} / \mathrm{v})$ ethanol for $5 \mathrm{~min}$.

\section{Ionomycin}

Each oocyte was transferred into TL-Hepes and ionomycin dissolved in dimethyl sulfoxide (DMSO) was added to the medium at a final concentration of 5 or $50 \mu \mathrm{M}$ [23]. The same amount of DMSO without ionomycin was added to control oocytes. For parthenogenetic development, the oocytes were incubated in TL-Hepes in the presence of 5 or $50 \mu \mathrm{M}$ ionomycin for $5 \mathrm{~min}$.

\section{Thimerosal}

By oxidizing sulfhydryl groups on critical $\mathrm{Ca}^{2+}$ release proteins thimerosal is known to elevate $\left[\mathrm{Ca}^{2+}\right]_{\mathrm{i}}$ in oocytes [24]. To assess whether thimerosal has the same effect in cats, individual oocytes were transferred into TL-Hepes and thimerosal dissolved in TL-Hepes was added at a final concentration of $200 \mu \mathrm{M}$ [25]. Because thimerosal oxidizes sulfhydryl groups on tubulin and thus damages the meiotic spindle, the application of a reducing agent such as dithiothreitol (DTT) is necessary to regenerate the spindle [26]. For activation, mature oocytes were treated according to two different schemes with the sulfhydryl modifying agents. In the first group, the oocytes were incubated in $200 \mu \mathrm{M}$ thimerosal for $15 \mathrm{~min}$ followed by a 30 -min incubation in the presence of $8 \mathrm{mM}$ DTT. Oocytes in the other group were exposed to $200 \mu \mathrm{M}$ thimerosal for $30 \mathrm{~min}$ followed by a $8 \mathrm{mM}$ DTT treatment for $20 \mathrm{~min}$.

\section{Strontium}

The oocytes were washed in $\mathrm{Ca}^{2+} / \mathrm{Mg}^{2+}$-free TL-Hepes medium and transferred to the measurement chamber containing $500 \mu \mathrm{l}$ of the same medium. After recording the baseline $\mathrm{Ca}^{2+}$ concentration, strontium-chloride $\left(\mathrm{SrCl}_{2}\right)$ dissolved in TL-Hepes was added at a final concentration of 10 or $20 \mathrm{mM}$ [27]. To induce development, oocytes were incubated in the presence of 10 or $20 \mathrm{mM}$ $\mathrm{SrCl}_{2}$ for $4 \mathrm{~h}$.

\section{$\mathrm{Na}^{+}$-free medium}

It was shown in pig oocytes that $\mathrm{Na}^{+}$-free medium can induce repetitive $\mathrm{Ca}^{2+}$ transients via the $\mathrm{Na}^{+} / \mathrm{Ca}^{2+}$ exchanger [28]. Based on this finding cat oocytes were placed individually into $10 \mu \mathrm{l}$ TL-Hepes. Following baseline detection, $2 \mathrm{ml} \mathrm{Na}{ }^{+}$-free medium was added to the medium that resulted in an approximately $200 \times$ dilution of the original $\mathrm{Na}^{+}$concentration. The $\mathrm{Na}^{+}$free medium consisted of choline chloride $114 \mathrm{mM}, \mathrm{KCl} 3.2 \mathrm{mM}$, $\mathrm{KH}_{2} \mathrm{PO}_{4} 0.4 \mathrm{mM}, \mathrm{MgCl}_{2} \times 6 \mathrm{H}_{2} \mathrm{O} 0.5 \mathrm{mM}$, Hepes $9.2 \mathrm{mM}$, $\mathrm{CaCl}_{2} \times 2 \mathrm{H}_{2} \mathrm{O} 2 \mathrm{mM}$, PVA 0.1\%, pH 7.0. For activation, 
mature oocytes were incubated in $\mathrm{Na}^{+}$-free medium for $15,30,45$ or $60 \mathrm{~min}$.

\section{Embryo culture and evaluation}

Potential zygotes were cultured (in groups of 10) in 100 $\mu \mathrm{l}$ drops of FOCM IVC-1 medium (FOCM supplemented with $0.4 \% \mathrm{BSA}$ ). To evaluate the formation of pronuclei the activated oocytes were cultured for $8 \mathrm{~h}$, then they were mounted on microscope slides under posted coverslips and placed in a fixative of ethanol: acetic acid (3:1) for 7 days. They were then stained with $1 \%(\mathrm{w} / \mathrm{v})$ aceto-orcein and evaluated for the presence or absence of pronuclei. In order to assess development to the blastocyst stage, after 3 days of culture the groups of embryos were transferred into $100 \mu \mathrm{l}$ drops of FOCM IVC-2 medium (FOCM supplemented with $5 \%$ fetal bovine serum) and incubated for an additional 4 days [20]. At the end of the 7-day culture period, the embryos were incubated in $5 \mu \mathrm{g} / \mathrm{ml}$ Hoechst 33342 for $15 \mathrm{~min}$ and the nuclei showing blue fluorescence were counted using an epifluorescence microscope.

\section{Somatic cell nuclear transfer}

\section{Preparation of donor cells}

The ultimate goal of these experiments was to generate cats as models for the heritable metabolic defect MPS I or AMD. The cell lines used as nuclear donors were generated by skin biopsies from affected cats. The explants were cut into small pieces and cultured in Dulbecco's Modified Eagle's medium (DMEM, Invitrogen) supplemented with $15 \%$ fetal bovine serum and 1\% penicillin/streptomycin. Small aliquots of cells between passages 3 and 5 were frozen in DMEM supplemented with 10\% DMSO and stored in liquid nitrogen until use.

\section{Oocyte collection}

Female cats were monitored daily for signs of behavioral estrus. Blood samples were collected from anestrual queens and the serum was assessed for progesterone to evaluate luteal status. Non-luteal queens were administered four intramuscular (i.m.) injections of porcine FSH at 24 h intervals (Day 1: 9.6 IU; Day 2: 7.6 IU; Day 3: 5.7 IU; Day 4: 5.7 IU); [29]. The last FSH injection was followed $24 \mathrm{~h}$ later by an i.m. injection of porcine $\mathrm{LH}(1,000$ IU). Donors were anesthetized 24-27 h after the LH injection and subjected to laparoscopy and follicle aspiration. Follicles $(2-5 \mathrm{~mm}$ in diameter) were aspirated and the COCs were collected in bicarbonate-buffered FOCM.

\section{Nuclear transfer}

Oocytes with an extruded polar body were enucleated in TL-Hepes medium supplemented with $7.5 \mu \mathrm{g} / \mathrm{ml}$ cytochalasin B. For enucleation, the first polar body and the adjacent cytoplasm presumably containing the metaphase-II chromosomes were removed. (Because in previous experiments this blind enucleation led to $\sim 85 \%$ successfully enucleated oocytes, Hoechst staining was not used during nuclear transfer in the present study). A donor cell was then transferred into the perivitelline space of each enucleated oocyte. Reconstructed oocytes were placed in an electroporation chamber filled with $\mathrm{Ca}^{2+}$-free electroporation medium (containing $300 \mathrm{mM}$ mannitol, $0.2 \mathrm{mM} \mathrm{MgSO}_{4}, 0.5 \mathrm{mM}$ Hepes, $0.1 \%$ polyvinyl alcohol) and two DC pulses $(1.2 \mathrm{kV} / \mathrm{cm}$ for $60 \mu \mathrm{sec}, 1 \mathrm{sec}$ apart) were applied. Following fusion, part of the reconstructed oocytes were activated by electroporation (two pulses of $1.0 \mathrm{kV} / \mathrm{cm}$ for $20 \mu \mathrm{sec}$ ) and the rest by the combined method of $15 \mathrm{~min}$ incubation with $200 \mu \mathrm{M}$ thimerosal followed by $30 \mathrm{~min}$ in $8 \mathrm{mM}$ DTT. Treated oocytes were transferred to FOCM supplemented with $10 \mu \mathrm{g} / \mathrm{ml}$ cycloheximide and $7.5 \mu \mathrm{g} / \mathrm{ml}$ cytochalasin B for $4 \mathrm{~h}$. Potential zygotes were then washed and cultured in FOCM $/ 0.4 \%$ BSA until embryo transfer.

\section{Embryo transfer}

Estrual females, on Day 2 to 6 of estrus received two subcutaneous injections of gonadotropin releasing hormone (GnRH; $25 \mu \mathrm{g}$ each, $12 \mathrm{~h}$ interval). The cats were anesthetized 54 to $58 \mathrm{~h}$ after the first GnRH injection and the ovaries were evaluated via laparoscopy. If fresh corpora lutea were present on the ovaries confirming the occurrence of recent ovulations, early cleavage stage (20-38 h after nuclear transfer) embryos ( $\mathrm{n}=8-21$ per animal) were transferred through the ostium into the lumen of the left or right oviduct. All embryo recipient queens were subjected to ultrasound examination 21-23 days after embryo transfer. Pregnant females were reassessed with ultrasonography periodically to monitor fetal viability and growth.

\section{Statistical analysis}

Frequencies of pronuclear formation, cleavage and blastocyst development were compared by the chi-square test. Total cell numbers of the blastocysts were compared by the Student's t-test. Statistical comparisons were performed using either SAS or Minitab; differences were considered significant at $\mathrm{P}<0.05$.

\section{Results \\ Changes in cytosolic $\mathrm{Ca}^{2+}$ levels}

Electroporation triggered an almost immediate rise in the $\left[\mathrm{Ca}^{2+}\right]_{\mathrm{i}}$ of cat oocytes. The application of DC pulses of larger voltage or longer duration led to more robust changes in cytoplasmic $\mathrm{Ca}^{2+}$ levels and increasing these parameters above a certain threshold (e.g. raising voltage above $\sim 1.8 \mathrm{kV} / \mathrm{cm}$ ) caused elevated intracellular $\mathrm{Ca}^{2+} \mathrm{lev}-$ els that did not return to baseline possibly indicating permanent membrane damage (data not shown). A typical change induced by two pulses of $1 \mathrm{kV} / \mathrm{cm}, 20 \mu \mathrm{sec}$ each is shown in Figure 1A. The resting $\left[\mathrm{Ca}^{2+}\right]_{\mathrm{i}}$ in the oocytes was approximately $200 \mathrm{nM}$. The $\left[\mathrm{Ca}^{2+}\right]_{i}$ elevation started $3 \pm$ 

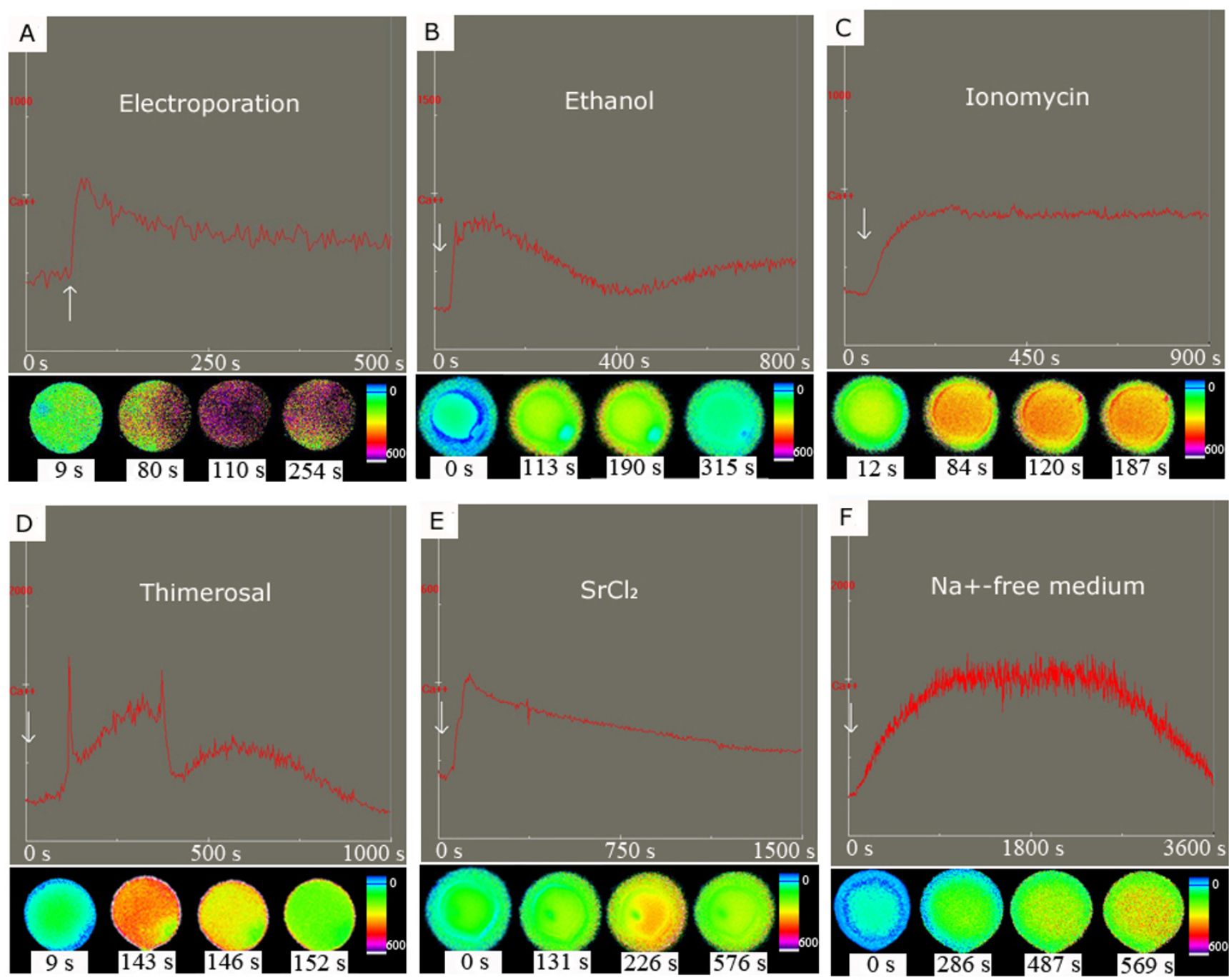

\section{Figure I}

Changes in the $\left[\mathrm{Ca}^{2+}\right]_{i}$ of cat oocytes induced by different stimuli. The upper part of each section shows cytoplasmic free $\mathrm{Ca}^{2+}$ levels as detected by a photometer; the arrows indicate the time when the stimulus was applied. In the lower part of each section images of $\left[\mathrm{Ca}^{2+}\right]_{i}$ changes in individual cat oocytes are shown; different colors indicate different intracellular free $\mathrm{Ca}^{2+}$ concentrations.

$0.4 \mathrm{sec}$ after applying the electrical shock and peaked at a concentration of $485 \pm 28 \mathrm{nM}$ after which it decreased gradually. The transient had an average duration of $73 \pm$ $15 \mathrm{sec}$ and the $\left[\mathrm{Ca}^{2+}\right]_{\mathrm{i}}$ reached near baseline levels by the end of the measurements $(n=15)$. Electroporation caused a single $\left[\mathrm{Ca}^{2+}\right]_{\mathrm{i}}$ rise in all oocytes tested (Table 1 ).

Incubation of mature cat oocytes in 7\% ethanol induced a single $\left[\mathrm{Ca}^{2+}\right]_{\mathrm{i}}$ rise in 5 out of 12 oocytes (Figure $1 \mathrm{~B}$ ). The elevation started at $110 \pm 11$ sec after adding the ethanol; the $\left[\mathrm{Ca}^{2+}\right]_{\mathrm{i}}$ then increased up to an average of $394 \pm 87 \mathrm{nM}$ and then returned to basal levels. The mean total duration of the $\mathrm{Ca}^{2+}$ transient was $150 \pm 41 \mathrm{sec}$. Ionomycin at both concentrations ( 5 and $50 \mu \mathrm{M}$ ) could elicit a rapid $\mathrm{Ca}^{2+}$ response in all (a total of 10) oocytes tested. Figure 1C shows a $\left[\mathrm{Ca}^{2+}\right]_{\mathrm{i}}$ change induced by $50 \mu \mathrm{M}$ ionomycin. The $\left[\mathrm{Ca}^{2+}\right]_{\mathrm{i}}$ rise in these cases started within a few seconds after adding ionomycin and peaked at a concentration of 336 $\pm 12 \mathrm{nM}$. In all cases the $\left[\mathrm{Ca}^{2+}\right]_{\mathrm{i}}$ elevation had an extended duration that lasted as long as the oocyte was exposed to the ionophore since no $\left[\mathrm{Ca}^{2+}\right]_{i}$ return to basal levels was observed during the measurement period. The $\mathrm{Ca}^{2+}$ rise triggered by $50 \mu \mathrm{M}$ ionomycin started within a shorter period of time and had higher amplitude compared to 
Table I: Characteristics of $\left[\mathrm{Ca}^{2+}\right]_{i}$ changes (mean \pm SEM) induced by various artificial stimuli

\begin{tabular}{|c|c|c|c|c|c|c|}
\hline Treatment & $\begin{array}{c}\text { No. of oocytes } \\
\text { (No. of responses) }\end{array}$ & $\begin{array}{c}\text { Time till response } \\
\text { (sec) }\end{array}$ & $\begin{array}{c}\text { Peak } \\
{\left[\mathrm{Ca}^{2+}\right]_{i}} \\
(\mathrm{nM})\end{array}$ & Duration (sec) & Oscillation & $\begin{array}{c}\text { Interval between } \\
\text { peaks (sec) }\end{array}$ \\
\hline Electroporation & $15(15)$ & $3 \pm 0.4$ & $485 \pm 28$ & $73 \pm 15$ & No & -- \\
\hline $7 \%$ ethanol & $5(12)$ & $\mid 10 \pm 31$ & $394 \pm 87$ & $150 \pm 4 \mid$ & No & -- \\
\hline $5 \mu \mathrm{M}$ ionomycin & $5(5)$ & $18 \pm 2$ & $277 \pm 27$ & $>800$ & No & -- \\
\hline $50 \mu \mathrm{M}$ ionomycin & $5(5)$ & $6 \pm 1$ & $336 \pm 12$ & $>800$ & No & -- \\
\hline $200 \mu \mathrm{M}$ thimerosal & $15(18)$ & $365 \pm 51$ & $496 \pm 75$ & $85 \pm 8$ & Yes & $351 \pm 30$ \\
\hline $20 \mathrm{mM} \mathrm{SrCl}_{2}$ & $15(15)$ & $85 \pm 10$ & $431 \pm 52$ & $335 \pm 28$ & No & -- \\
\hline $\mathrm{Na}^{+}$-free medium & $15(28)$ & $135 \pm 24$ & $639 \pm 79$ & $1470 \pm 242$ & No & -- \\
\hline
\end{tabular}

those stimulated by lower ionomycin concentration (data not shown). DMSO alone did not elicit changes in the $\left[\mathrm{Ca}^{2+}\right]_{\mathrm{i}}$ (data not shown).

Incubation of mature cat oocytes with $200 \mu \mathrm{M}$ thimerosal induced $\left[\mathrm{Ca}^{2+}\right]_{\mathrm{i}}$ elevation in 15 out of 18 oocytes; the signal took place as an oscillation in the intracytoplasmic $\mathrm{Ca}^{2+}$ level in 11 oocytes. On average, the initial $\left[\mathrm{Ca}^{2+}\right]_{\mathrm{i}}$ rise started $356 \pm 51 \mathrm{sec}$ after the addition of thimerosal, with an average peak concentration of $496 \pm 75 \mathrm{nM}$ and a mean duration of $85 \pm 8 \mathrm{sec}$. Subsequent rises in the $\left[\mathrm{Ca}^{2+}\right]_{\mathrm{i}}$ were generated at intervals of $351 \pm 30 \mathrm{sec}$; the number of $\mathrm{Ca}^{2+}$ spikes induced in the oocytes was between 2 and 5. In all oocytes the initial transient had the highest peak, each subsequent transient tended to have a lower average amplitude (Figure 1D). The oscillations usually lasted for 30-45 min and during this time the $\mathrm{Ca}^{2+}$ baseline increased gradually.

Addition of $\mathrm{SrCl}_{2}$ caused a single long-lasting rise in the $\left[\mathrm{Ca}^{2+}\right]_{\mathrm{i}}$ in all oocytes tested $(\mathrm{n}=30)$. As a result of $20 \mathrm{mM}$ $\mathrm{SrCl}_{2}$ stimulation, the baseline $\left[\mathrm{Ca}^{2+}\right]_{\mathrm{i}}$ increased to $431 \pm$ $52 \mathrm{nM}$ within $85 \pm 10 \mathrm{sec}$. The average duration of the elevated $\left[\mathrm{Ca}^{2+}\right]_{i}$ was $335 \pm 28 \mathrm{sec}$ (Figure $1 \mathrm{E}$ ). The lower (10 $\mathrm{mM}) \mathrm{SrCl}_{2}$ concentration elicited a similar response in the $\left[\mathrm{Ca}^{2+}\right]_{\mathrm{i}}$ (data not shown).

The profile of the $\left[\mathrm{Ca}^{2+}\right]_{\mathrm{i}}$ rise caused by $\mathrm{Na}^{+}$-free-medium is displayed in Figure 1F. Incubation in $\mathrm{Na}^{+}$-free-medium induced a gradual $\left[\mathrm{Ca}^{2+}\right]_{i}$ elevation in 15 out of 28 oocytes. The rise started $135 \pm 24 \mathrm{sec}$ after addition of the $\mathrm{Na}^{+}$-free-medium and peaked at a concentration of $639 \pm$ $79 \mathrm{nM}$. The average duration of the $\left[\mathrm{Ca}^{2+}\right]_{i}$ rise induced by the $\mathrm{Na}^{+}$-free-medium was $1,470 \pm 242 \mathrm{sec}$.

\section{Parthenogentic embryo development}

The fluorescence recordings indicated that all the artificial stimuli tested were able to generate an elevation in the $\left[\mathrm{Ca}^{2+}\right]_{\mathrm{i}}$ in mature cat oocytes. Next, in preliminary experiments the different stimuli were evaluated for their ability to induce parthenogenetic development and based on the outcome of these experiments four different treatments were finally selected and compared. The treatments selected for further evaluation were the following: 1) electroporation using two DC pulses of $1.0 \mathrm{kV} / \mathrm{cm}$ for $20 \mu \mathrm{sec}$ each; 2) 15 min incubation in $200 \mu \mathrm{M}$ thimerosal followed by a culture in $8 \mathrm{mM}$ DTT for $30 \mathrm{~min} ; 3$ ) incubation in the presence of $20 \mathrm{mM} \mathrm{SrCl}{ }_{2}$ in $\mathrm{Ca}^{2+} / \mathrm{Mg}^{2+}$-free medium for $4 \mathrm{~h}$, and 4) a treatment in $\mathrm{Na}^{+}$-free medium for 45 min. Each treatment was applied with or without subsequent incubation in the presence of $10 \mu \mathrm{g} / \mathrm{ml}$ cycloheximide and $7.5 \mu \mathrm{g} / \mathrm{ml}$ cytochalasin B for $4 \mathrm{~h}$.

Electroportation stimulated 72 out of $119(60.5 \pm 2.9 \%)$ oocytes to form pronuclei. Incubation of the electroporated oocytes with cycloheximide and cytochalasin $\mathrm{B}$ increased the percentage of oocytes having pronuclei significantly ( 65 out of $81,80.2 \pm 3.1 \%, \mathrm{P}<0.05$ ). The combined thimerosal/DTT treatment induced pronuclear formation in 84 out of 124 oocytes $(67.7 \pm 1.8 \%)$, this frequency was significantly higher than those found after the $20 \mathrm{mM} \mathrm{SrCl}_{2}(58 / 114 ; 50.9 \pm 4.0 \%)$ and $\mathrm{Na}^{+}$-free medium $(62 / 115 ; 53.9 \pm 2.4 \%)$ treatments $(\mathrm{P}<0.05)$. Oocytes in these groups tended to show higher pronuclear formation after cycloheximide and cytochalasin B incubation but the difference was not statistically significant (Figure 2).

The cleavage frequency stimulated by electroporation was $58.2 \pm 4.0 \%$ (142 out of 244 oocytes; Figure 3$)$. The thimerosal/DTT treatment triggered $60.6 \pm 2.4 \%$ (154/ 254 ) of the oocytes to cleave, this percentage was significantly higher than that registered in the $\mathrm{SrCl}_{2}$-treated group (128/262; $48.9 \pm 3.6 \%$; $<<0.05)$. Of the oocytes that were activated with $\mathrm{Na}^{+}$-free medium, $54.9 \pm 3.4 \%$ $(162 / 295)$ cleaved. We also found that incubation with cycloheximide and cytochalasin B caused a significant increase in cleavage frequency after electroporation (140/ $203 ; 69 \pm 4.2 \%)$ and $\mathrm{SrCl}_{2}(118 / 201 ; 58.7 \pm 4.5 \%)$ treatments $(\mathrm{P}<0.05)$.

In the absence of incubation with the inhibitors, blastocyst formation was the highest after electroporation (28/ $244 ; 11.5 \pm 1.7 \%)$ and the combined thimerosal/DTT treatment $(27 / 254 ; 10.6 \pm 1.9 \%)$. These values were 


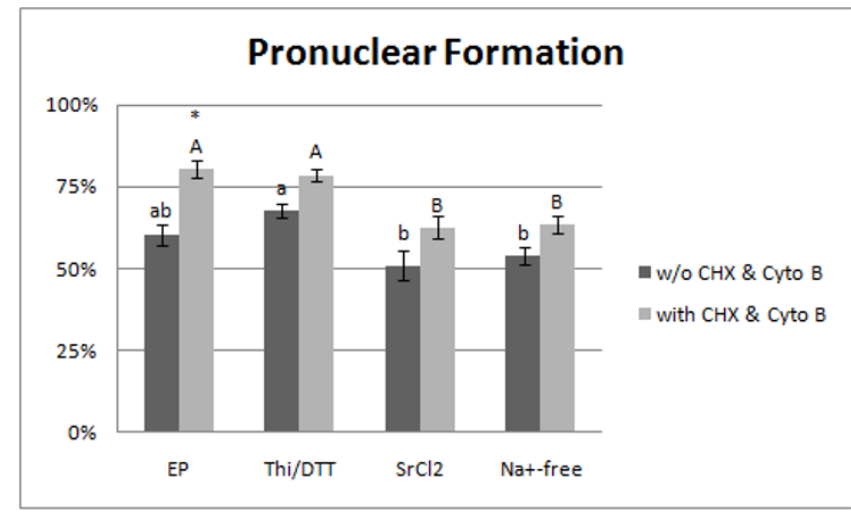

Figure 2

Pronuclear formation in cat oocytes activated by electroporation (EP), thimerosal/DTT (Thi/DTT), $\mathrm{SrCl}_{2}$ and $\mathrm{Na}^{+}$-free medium ( $\mathrm{Na}^{+}$-free) with or without 4-h incubation in cycloheximide (CHX) and cytochalasin B (Cyto B). The asterisk indicates a significant difference $(P<0.05)$ between frequencies of pronuclear formation achieved with and without $\mathrm{CHX/Cyto} \mathrm{B} \mathrm{supplemen-}$ tation. Different lowercase letters indicate significant differences between treatments without $\mathrm{CHX/Cyto} \mathrm{B} \mathrm{sup-}$ plementation $(P<0.05)$; different uppercase letters indicate significant differences between treatments that were followed by $\mathrm{CHX} / \mathrm{Cyto} \mathrm{B}$ incubation $(\mathrm{P}<0.05)$.

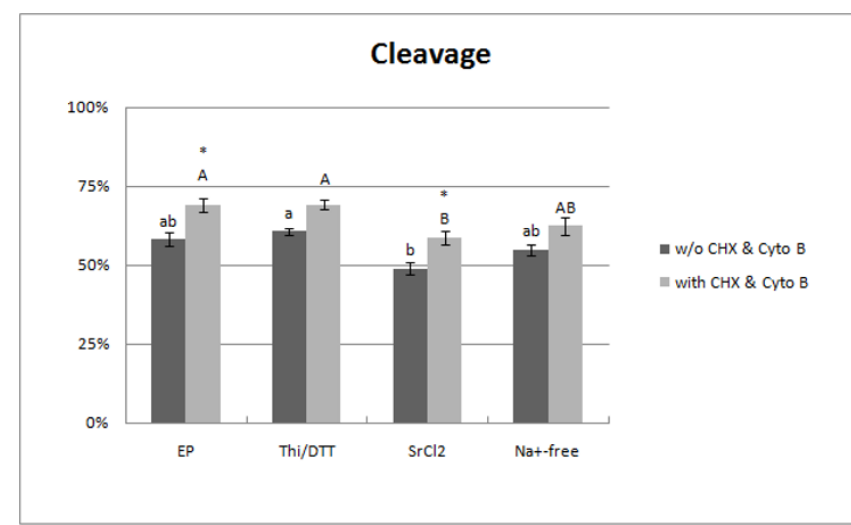

Figure 3

Cleavage development of embryos after activation by electroporation (EP), thimerosal/DTT (Thi/DTT), $\mathrm{SrCl}_{2}$ and $\mathrm{Na}^{+}$-free medium ( $\mathrm{Na}^{+}$-free) with or without a 4-h incubation in cycloheximide $(\mathrm{CHX})$ and cytochalasin B (Cyto B). The asterisks indicate significant differences $(P<0.05)$ between cleavage frequencies achieved with and without $\mathrm{CHX/Cyto} \mathrm{B} \mathrm{supplementation.} \mathrm{Different}$ lowercase letters indicate significant differences between treatments without $\mathrm{CHX/Cyto} \mathrm{B} \mathrm{supplementation}(\mathrm{P}<0.05)$; different uppercase letters indicate significant differences between treatments where the $\mathrm{Ca}^{2+}$ signal-inducing stimulus was followed by $\mathrm{CHX} / \mathrm{Cy}$ to $\mathrm{B}$ incubation $(\mathrm{P}<0.05)$. significantly higher than those in the $\operatorname{SrCl}_{2}(12 / 262 ; 4.6 \pm$ $3.6 \%)$ and $\mathrm{Na}^{+}$-free medium $(16 / 295 ; 5.4 \pm 3.4 \%)$ treated groups $(\mathrm{P}<0.05$; Figure 4$)$. Incubation with cycloheximide and cytochalasin B significantly improved the frequency of blastocyst formation in oocytes that were activated by thimerosal/DTT (44/209; $16.7 \pm 2.9 \%), \mathrm{SrCl}_{2}$ $(24 / 201 ; 11.9 \pm 2.8 \%)$ and $\mathrm{Na}^{+}$-free medium $(24 / 245 ; 9.8$ $\pm 1.4 \%) ;(\mathrm{P}<0.05)$.

\section{Somatic cell nuclear transfer}

A total of 157 reconstructed oocytes were produced by somatic cell nuclear transfer using MPS I-affected donor cells; these oocytes were activated by electroporation followed by incubation in cycloheximide and cytochalasin B. Following activation $114(72.6 \%)$ reconstructed oocytes cleaved, the 2 to 4 -cell embryos were transferred into the oviducts of 9 recipient females. Three of these recipients had implantations on initial palpation and ultrasonographic exam on Day 20 to 21 post-transfer. During early ultrasonography a total of 4 implantation sites and 3 developing fetuses were found; one female had only a single implantation site with no visible fetus. Heartbeats were successfully detected in two of the fetuses. However, by day 47 all 3 fetuses were absorbed (Table 2). An additional 130 reconstructed oocytes were produced by nuclear transfer using AMD-affected donor cells; 73 of which were activated by electroporation followed by cycloheximide and cytochalasin B incubation while 57 were activated by thimerosal/DTT followed by incubation with the inhibitors. In the electroporation-

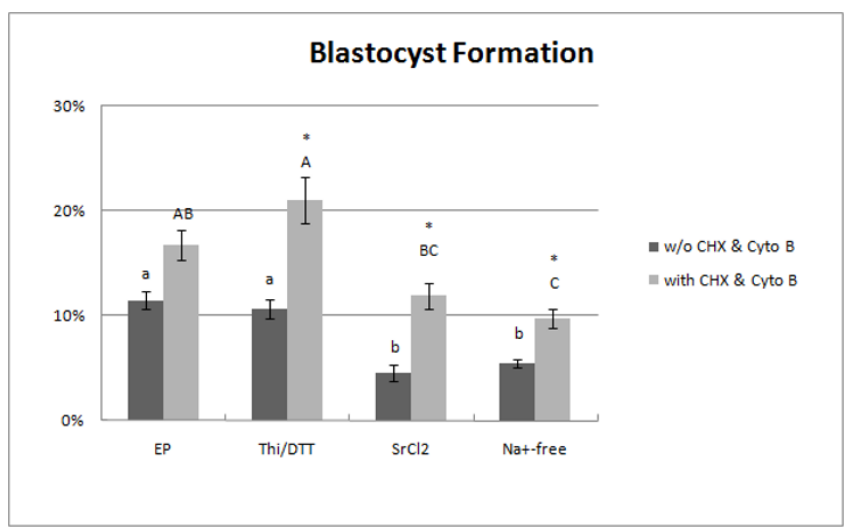

Figure 4

Blastocyst formation induced by parthenogenetic activation of cat oocytes. The asterisks indicate significant differences $(P<0.05)$ between frequencies of blastocyst formation achieved with and without $\mathrm{CHX/Cyto} \mathrm{B} \mathrm{supplemen-}$ tation. Different lowercase letters indicate significant differences between treatments without $\mathrm{CHX/Cyto} \mathrm{B} \mathrm{sup-}$ plementation; different uppercase letters indicate significant differences between treatments followed by $\mathrm{CHX/Cyto} \mathrm{B}$ incubation $(P<0.05)$. 
Table 2: Development of reconstructed cat oocytes activated by electroporation or thimerosal/DTT.

\begin{tabular}{ccccccc}
\hline $\begin{array}{c}\text { Donor Cell } \\
\text { type }\end{array}$ & $\begin{array}{c}\text { Activation } \\
\text { treatment }\end{array}$ & $\begin{array}{c}\text { Embryos } \\
\text { produced }\end{array}$ & $\begin{array}{c}\text { Embryos cleaved } \\
\text { and transferred } \\
(\%)\end{array}$ & $\begin{array}{c}\text { Recipients } \\
\text { Pregnant }\end{array}$ & $\begin{array}{c}\text { Implantation } \\
\text { sites (\%) }\end{array}$ & $\begin{array}{c}\text { No. of fetuses } \\
\text { (\%) }\end{array}$ \\
\hline MPS & Electroporation & 157 & $114(72.6)$ & 9 & $2 *$ & $4(3.5)$ \\
AMD & Electroporation & 73 & $62(84.9)$ & 6 & 2 & $4(6.5)$ \\
AMD & Thimerosal/DTT & 57 & $44(77.2)$ & 4 & 0 & $2(3.6)$ \\
$0(0)$ & $0(0)$ \\
\hline
\end{tabular}

Stimulated oocytes in both cases were subsequently incubated in cycloheximide and cytochalasin B for $4 \mathrm{~h}$.

*A third female had a single implantation site but with no observable fetus

activated group 62 oocytes (84.9\%) cleaved; cleavage frequency in the thimerosal/DTT-treated group was $77.2 \%$ (44 out of 57 oocytes). The 62 cleaved embryos that were produced by electroporation were transferred into 6 recipients, of which 2 became pregnant. In the pregnant animals 4 implantation sites and 2 fetuses were detected on day 21. The 2 to 4 -cell embryos that resulted from the thimerosal/DTT activation were transferred into 4 recipients; ultrasonography on day 21 could find neither implantation sites nor developing fetuses in these surrogates. No fetuses could be detected by ultrasonography on day 49 in any of the recipient animals.

\section{Discussion}

Following sperm-oocyte fusion, the $\mathrm{Ca}^{2+}$ signal triggered by the fertilizing sperm is responsible for stimulating meiotic resumption and eventually, embryonic development. In most cases, parthenogenetic activation methods also induce an elevation in the $\left[\mathrm{Ca}^{2+}\right]_{i}$ to activate the oocyte's developmental program [5]. In many species numerous comparative studies have been carried out using different methods of artificial activation, and the most effective ones have been selected to activate reconstructed oocytes after nuclear transfer. In felids no such studies have been performed and the number of methods available for parthenogenetic activation of cat oocytes is rather limited. In the present study we characterized responses of cat oocytes to several artificial stimuli in order to find ways to trigger $\left[\mathrm{Ca}^{2+}\right]_{\mathrm{i}}$ changes similar to those detected during mammalian fertilization. All the methods tested could elicit a rise in the $\left[\mathrm{Ca}^{2+}\right]_{\mathrm{i}}$ of cat oocytes. Electroporation is commonly used to induce a transient elevation in the $\left[\mathrm{Ca}^{2+}\right]_{\mathrm{i}}$ of oocytes of various species; it has also been successfully used to stimulate oocyte activation during cat nuclear transfer [30]. The short, high voltage DC pulses are known to induce a significant transmembrane $\mathrm{Ca}^{2+}$ influx by causing a destabilization of the phospholipid bilayer. The influx is influenced by the voltage and duration of the electrical pulse as well as the ionic strength of the electroporation medium [31]. We evaluated the effect of DC pulses with various duration and magnetic field characteristics; all pulses triggered changes in the $\left[\mathrm{Ca}^{2+}\right]_{\mathrm{i}}$. To stimulate embryonic development we have selected a set of parameters that induced a large $\left[\mathrm{Ca}^{2+}\right]_{i}$ elevation without causing irreversible damage to the oocytes.

Ethanol was reported to activate oocytes of various species. In Xenopus it was demonstrated to stimulate the production of inositol 1,4,5-trisphosphate $\left(\mathrm{IP}_{3}\right)$ which induces the release of $\mathrm{Ca}^{2+}$ from the oocyte's intracellular stores [32]. Its effect on cytoplasmic $\mathrm{Ca}^{2+}$ levels of cat oocytes has never been characterized before. We found that $7 \%$ ethanol triggered a long-lasting $\mathrm{Ca}^{2+}$ signal in cat oocytes as well. However, the effects of ethanol on subsequent embryonic development have not been tested in the present study because recently it was shown by others that ethanol could activate $~ 50 \%$ of cat oocytes [8]. The $\mathrm{Ca}^{2+}$ ionophore ionomycin has also been shown to induce $\left[\mathrm{Ca}^{2+}\right]_{i}$ elevations in occytes of many species. According to the literature, the parameters of ionomycin treatment used to activate oocytes of various species vary significantly: concentrations ranging from $5 \mu \mathrm{M}$ to $5 \mathrm{mM}$ [33] and treatment duration of $1 \mathrm{~min}$ to $40 \mathrm{~min}$ have also been reported [34]. The influence of ionomycin on cat oocytes has never been described; therefore optimizing the concentration and incubation time is critical for successful oocyte activation. As in other species, cat oocytes showed a larger elevation in the intracellular free $\mathrm{Ca}^{2+} \mathrm{lev}-$ els after being treated with higher concentrations of ionomycin. Surprisingly, all the ionomycin concentrations that we tested for the ability to induce $\left[\mathrm{Ca}^{2+}\right]_{i}$ changes caused irreversible damages and were lethal to the oocytes.

Thimerosal is known to oxidize sulfhydryl groups on intracellular $\mathrm{Ca}^{2+}$ release proteins [35,36], thus causing the release of stored $\mathrm{Ca}^{2+}$ and oscillation in the $\left[\mathrm{Ca}^{2+}\right]_{\mathrm{i}} \mathrm{lev}-$ els in oocytes of a number of species [24,26,37]. Similar to those findings, thimerosal in cat oocytes was able to induce repetitive $\left[\mathrm{Ca}^{2+}\right]_{i}$ changes. During incubation, the baseline $\left[\mathrm{Ca}^{2+}\right]_{\mathrm{i}}$ became increasingly elevated between transients that was probably attributable to the inhibition of $\mathrm{Ca}^{2+}$-ATPases since it was reported that thimerosal not only induced $\mathrm{Ca}^{2+}$ release from the stores but also inhibited $\mathrm{Ca}^{2+}$-ATPases and prevented the removal of excess $\mathrm{Ca}^{2+}$ from the cytosol [38]. 
Incubation in the presence of $\mathrm{Sr}^{2+}$ induces activation in mouse oocytes [39] but the mechanism of its action has not been completely elucidated. Because in certain cell types $\mathrm{Sr}^{2+}$ is handled similar to $\mathrm{Ca}^{2+}$ it was proposed that $\mathrm{Sr}^{2+}$ activates oocytes by displacing bound $\mathrm{Ca}^{2+}[40]$. Recent studies showed that by using a low molecular weight heparin to antagonize the function of $\mathrm{IP}_{3}$ receptors or treating oocytes with the phospholipase $\mathrm{C}$ inhibitor U73122, the $\mathrm{Sr}^{2+}$-induced $\left[\mathrm{Ca}^{2+}\right]_{i}$ increases in mouse oocytes were blocked and this inhibitory effect could be rescued by microinjection of $\mathrm{IP}_{3}$. These results indicated that $\mathrm{Sr}^{2+}$ triggered the release of stored $\mathrm{Ca}^{2+}$ through the $\mathrm{IP}_{3}$ receptors [41]. Although in mice $\mathrm{Sr}^{2+}$ treatment leads to an oscillation in the oocyte $\left[\mathrm{Ca}^{2+}\right]_{\mathrm{i}}$, we found that in cat oocytes $\mathrm{Sr}^{2+}$ triggered a single, long-lasting $\mathrm{Ca}^{2+}$ elevation.

The effects of $\mathrm{Na}^{+}$-free medium have been described in the pig where it was reported to induce oscillatory changes in the $\left.\left[\mathrm{Ca}^{2+}\right]_{i ;} ; 28\right]$. In approximately $50 \%$ of the cases, $\mathrm{Na}^{+}$ free medium also stimulated a $\left[\mathrm{Ca}^{2+}\right]_{\mathrm{i}}$ elevation in cat oocytes with a high amplitude and long duration. The effect of the $\mathrm{Na}^{+}$-free medium is probably mediated by the $\mathrm{Na}^{+} / \mathrm{Ca}^{2+}$ exchanger expressed in the plasma membrane of cat oocytes. The $\mathrm{Na}^{+} / \mathrm{Ca}^{2+}$ exchanger uses the energy of a $\mathrm{Na}^{+}$gradient to move $\mathrm{Ca}^{2+}[42]$. However, in case of low extracellular $\mathrm{Na}^{+}$levels the exchanger can operate in a reverse mode, pumping $\mathrm{Ca}^{2+}$ into the cell. This feature of the exchanger makes $\mathrm{Na}^{+}$-free medium a potential candidate for stimulating oocyte activation. The exchanger was found to be present in hamster [43], mouse $[44,45]$ and porcine [28] oocytes. Because $\mathrm{Na}^{+}-$free medium triggered an elevation in the $\left[\mathrm{Ca}^{2+}\right]_{i}$ we decided to investigate its ability to stimulate parthenogenetic development in cat oocytes.

Based on the results of the fluorescence measurements, four different methods have been selected to activate cat oocytes. As a result of the treatments, pronuclear formation in the oocytes ranged between $50.9 \%$ and $67.7 \%$. The combined thimerosal/DTT treatment followed by cycloheximide and cytochalasin B incubation led to blastocyst formation in $21.1 \%$ of the cases. This frequency is similar to that received after electroporation, the method most widely used for oocyte activation. Although thimerosal is able to induce $\mathrm{Ca}^{2+}$ oscillation in oocytes, it also oxidizes sulfhydryl groups on tubulin that prevents further development [46]. In order to eliminate its negative effects, the thimerosal treatment must be followed by an incubation in the presence of the sulfhydryl-reducing compound DTT [26]. The high percentage of blastocyst formation achieved in the present study indicates for the first time that the thimerosal/DTT activation is an effective way to stimulate parthenogenetic embryo development in cats.
Even though blastocyst formations induced by $\mathrm{SrCl}_{2}$ or $\mathrm{Na}^{+}$-free medium were somewhat low, this is the first report to demonstrate that these stimuli can trigger cat oocyte activation and subsequent blastocyst development. Although $\mathrm{Na}^{+}$-free medium has previously been reported to induce $\left[\mathrm{Ca}^{2+}\right]_{\mathrm{i}}$ increases in porcine oocytes, no subsequent embryo development has been observed [28]. Here we found that $\mathrm{Na}^{+}$-free medium could induce cleavage of cat oocytes with a frequency similar to that triggered by electroporation or the combined thimerosal/DTT treatment, although the subsequent blastocyst formation was lower compared to the other treatments. It is possible that the amplitude of the $\mathrm{Ca}^{2+}$ signal induced by the $\mathrm{Na}^{+}$-free medium is insufficient to induce complete egg activation. This is in accordance with the finding that in rabbit the amplitude of the $\mathrm{Ca}^{2+}$ transient did not appear to affect early cleavage but it influenced the developmental competence of the produced embryo [7]. Another reason for the low blastocyst formation may be that sustained high levels of $\left[\mathrm{Ca}^{2+}\right]_{i}$ induced via the $\mathrm{Na}^{+} / \mathrm{Ca}^{2+}$ exchanger caused cellular damage that negatively influenced developmental competence. Although optimization of the $\mathrm{Na}^{+}$-free treatment was attempted in this study, the improvement in embryonic development was not significant. Additional studies focusing on the fine-tuning of this method may be helpful to develop a method that utilizes the $\mathrm{Ca}^{2+}$ signal generated via the $\mathrm{Na}^{+} / \mathrm{Ca}^{2+}$ exchanger for oocyte activation.

The results obtained also showed that incubation of cat oocytes in cycloheximide and cytochalasin B after an induced $\mathrm{Ca}^{2+}$ signal increased the frequency of pronuclear formation, cleavage and blastocyst formation. Mature mammalian oocytes arrested at the second metaphase stage synthesize cyclin B continuously in order to maintain activity of the M-phase Promoting Factor (MPF). During activation, MPF activity has to drop in order to allow release from the metaphase II arrest [47]. Cycloheximide is a protein synthesis inhibitor that blocks the production of cyclin B and in turn decreases MPF activity. Cytochalasin $B$ on the other hand is an inhibitor of actin polymerization frequently used to block the extrusion of second polar body. In the presence of cytochalasin B, segregation of the chromosomes occurs after parthenogenetic oocyte activation but cytokinesis does not take place which results in the formation of diploid zygotes with two pronuclei $[22,48]$. In our experiments, incubation of cat oocytes with cycloheximide and cytochalasin $\mathrm{B}$ had the tendency to improve pronuclear formation, cleavage frequency and blastocyst development after every single $\mathrm{Ca}^{2+}$ elevation-inducing stimulus tested and the improvement was significant in several cases. Although the incubation did not increase the total cell number of the developing blastocysts, the results indicate that these inhibitors are 
beneficial to increase the efficiency of oocyte activation in the cat.

The objective of the oocyte activation experiments was to develop potential methods to be used during nuclear transfer for the generation of useful disease models. In the domestic cat, somatic cell nuclear transfer not only provides the opportunity to generate genetically identical animals for research purposes, it also has the potential to facilitate preservation of rare and valuable felid populations, including cat research models and possibly endangered felid species [30]. In addition, domestic cats are useful research models for the study of more than 200 human hereditary diseases [49]. Maintenance of cat disease models can be challenging however, because the disease state may interfere with normal breeding, gestation and/or parturition. The application of nuclear transfer technology offers an innovative approach. Cloning would eliminate the need to collect gametes from affected animals for in vitro fertilization, it would obviate the requirement to maintain populations of carrier (heterozygous) cats, and for cat models that do not survive to sexual maturity cloning would provide a direct method for their continued propagation. Based on the frequency of blastocyst formation they induced, two methods were selected to activate reconstructed cat oocytes after nuclear transfer. These methods included electroporation and the combined thimerosal/DTT treatment, each followed by incubation in the presence of cycloheximide and cytochalasin B.

For nuclear transfer, fibroblast cells from two animals affected by different metabolic defects were collected and used as nuclear donors. The defects included AMD and MPS I, two lysosomal storage diseases that have been extensively characterized in cats. They are homologous to human inborn errors, involve single gene mutations and inherited as autosomal recessive traits $[49,50]$. These models have been instrumental in demonstrating the value of bone marrow transplantation in alleviating these diseases and, most recently, the potential of gene therapy using an adeno-associated viral vector for treating AMDaffected cats $[14,15]$. Cats affected with MPS I are difficult to breed naturally due to musculoskeletal abnormalities whereas AMD-affected cats typically die before reaching puberty.

Transfer of cloned embryos in which development was stimulated with electroporation followed by cycloheximide and cytochalasin B incubation resulted in 5 females having distinct implantation sites and 4 females with established pregnancies (i.e., presence of at least one fetus). Despite a total of 8 implantation sites, 5 fetuses and detectable heartbeats in two fetuses, no term development occurred; all fetuses were eventually reabsorbed by day 49 of pregnancy. Our previous research has demonstrated the developmental competence to term of MPSaffected and MPS-carrier IVF embryos following transfer into our primary recipient type [51]. Pregnancy loss in the current study may be attributable to deficient reprogramming of the donor nucleus in the enucleated oocyte or aberrant chromosome numbers as a result of incomplete enucleation. Furthermore, no pregnancies were detected following thimerosal/DTT-induced oocyte activation which was somewhat unexpected. Nevertheless, the thimerosal/DTT treatment stimulated cleavage divisions at a frequency comparable to that achieved by electroporation. This, in light of a recent report showing that the thimerosal/DTT activation supported term development of cloned transgenic piglets [52] implies that successful activation can be achieved by modification of sulfhydryl groups on key $\mathrm{Ca}^{2+}$ releasing proteins in cat oocytes.

\section{Conclusion}

This study described a number of novel methods to induce $\mathrm{Ca}^{2+}$ release in cat oocytes for the stimulation of embryo development. In addition, the results support previous findings that electroporation is an effective way for the activation of oocytes reconstructed by nuclear transfer. Based on in vitro data, the combined thimerosal/DTT activation may also be suitable for cat oocyte activation but this needs further verification from additional studies.

\section{Competing interests}

The authors declare that they have no competing interests.

\section{Authors' contributions}

$\mathrm{CW}$ carried out in vitro oocyte maturation, fluorescence measurements, parthenogenetic oocyte activation, performed statistical analysis and drafted the manuscript. WFS conceived of the study, participated in its design and performed oocyte collections and embryo transfers. JRH participated in oocyte collections and embryo transfers. $\mathrm{KL}$ performed nuclear transfer. ZM participated in the design and coordination of the study and helped to draft the manuscript. All authors read and approved the final manuscript.

\section{Acknowledgements}

This research was supported by NIH grants from the National Center for Research Resources to W. Swanson (RR-I5388) and to M. Haskins (RR025I2). The authors would like to thank G. Margarey at the Cincinnati Zoo \& Botanical Garden and M. Haskins at the School of Veterinary Medicine, University of Pennsylvania for providing the somatic cell lines from cat hereditary disease models used for this study. The assistance of animal care and research staff $(\mathrm{H}$. Bateman, J. Bond, J. Newsom) at the Cincinnati Zoo also is greatly appreciated.

\section{References}

I. Sagata N: Meiotic metaphase arrest in animal oocytes: its mechanisms and biological significance. Trends Cell Biol 1996, 6(I):22-28. 
2. Cuellar O: Animal parthenogenesis. Science 1977, 197(4306):837-843.

3. Whitaker M, Larman MG: Calcium and mitosis. Semin Cell Dev Biol 200I, I 2(I):53-58.

4. Alberio R, Zakhartchenko V, Motlik J, Wolf E: Mammalian oocyte activation: lessons from the sperm and implications for nuclear transfer. Int J Dev Biol 200I, 45(7):797-809.

5. Machaty Z, Prather RS: Strategies for activating nuclear transfer oocytes. Reprod Fertil Dev 1998, 10(7-8):599-6|3.

6. Fulton BP, Whittingham DG: Activation of mammalian oocytes by intracellular injection of calcium. Nature 1978, 273(5658): |49-|5|

7. Ozil JP, Huneau D: Activation of rabbit oocytes: the impact of the $\mathrm{Ca}^{2+}$ signal regime on development. Development 200I, 128(6):917-928.

8. Grabiec A, Max A, Tischner M: Parthenogenetic activation of domestic cat oocytes using ethanol, calcium ionophore, cycloheximide and a magnetic field. Theriogenology 2007, 67(4):795-800.

9. Shelton GD, Engvall E: Canine and feline models of human inherited muscle diseases. Neuromuscul Disord 2005, I5(2): I 27- 138.

10. Dias AS, Bester MJ, Britz RF, Apostolides Z: Animal models used for the evaluation of antiretroviral therapies. Curr HIV Res 2006, 4(4):43I-446.

II. Coyne KP, Edwards D, Radford AD, Cripps P, Jones D, Wood JL, Gaskell RM, Dawson S: Longitudinal molecular epidemiological analysis of feline calicivirus infection in an animal shelter: a model for investigating calicivirus transmission within highdensity, high-turnover populations. J Clin Microbiol 2007, 45( I 0):3239-3244.

12. Gillick M, Linn K: Rotating dome trochleoplasty: an experimental technique for correction of patellar luxation using a feline model. Vet Comp Orthop Traumatol 2007, 20(3): I80-184.

13. Wakeling J, Smith K, Scase T, Kirkby R, Elliott J, Syme H: Subclinical hyperthyroidism in cats: a spontaneous model of subclinical toxic nodular goiter in humans? Thyroid 2007, I 7(12): I 20I-I 209.

14. Ellinwood NM, Vite CH, Haskins ME: Gene therapy for lysosomal storage diseases: the lessons and promise of animal models. $J$ Gene Med 2004, 6(5):48I-506.

15. Vite $\mathrm{CH}$, McGowan JC, Niogi SN, Passini MA, Drobatz KJ, Haskins $\mathrm{ME}$, Wolfe JH: Effective gene therapy for an inherited CNS disease in a large animal model. Ann Neurol 2005, 57(3):355-364.

16. Luvoni GC, Pellizzari P: Embryo development in vitro of cat oocytes cryopreserved at different maturation stages. Theriogenology 2000, 53(8): I529-1540.

17. Gomez MC, Jenkins JA, Giraldo A, Harris RF, King A, Dresser BL, Pope CE: Nuclear transfer of synchronized african wild cat somatic cells into enucleated domestic cat oocytes. Biol Reprod 2003, 69(3):|032-104|.

18. Swanson WF: Application of assisted reproduction for population management in felids: the potential and reality for conservation of small cats. Theriogenology 2006, 66(I):49-58.

19. Gomez MC, Pope CE, Giraldo A, Lyons LA, Harris RF, King AL, Cole A, Godke RA, Dresser BL: Birth of African Wildcat cloned kittens born from domestic cats. Cloning Stem Cells 2004, 6(3):247-258.

20. Herrick JR, Bond JB, Magarey GM, Bateman HL, Krisher RL, Dunford SA, Swanson WF: Toward a feline-optimized culture medium: impact of ions, carbohydrates, essential amino acids, vitamins, and serum on development and metabolism of in vitro fertilization-derived feline embryos relative to embryos grown in vivo. Biol Reprod 2007, 76(5):858-870.

21. Machaty Z: Activation of oocytes after nuclear transfer. Methods Mol Biol 2006, 348:43-58.

22. Presicce GA, Yang X: Parthenogenetic development of bovine oocytes matured in vitro for $\mathbf{2 4} \mathrm{hr}$ and activated by ethanol and cycloheximide. Mol Reprod Dev 1994, 38(4):380-385.

23. Heytens E, Soleimani R, Lierman S, De Meester S, Gerris J, Dhont M, Elst J Van der, De Sutter P: Effect of ionomycin on oocyte activation and embryo development in mouse. Reprod Biomed Online 2008, I7(6):764-77|.

24. Swann K: Thimerosal causes calcium oscillations and sensitizes calcium-induced calcium release in unfertilized hamster eggs. FEBS Lett I99|, 278(2): |75-I78.
25. Im GS, Seo JS, Hwang IS, Kim DH, Kim SW, Yang BC, Yang BS, Lai L, Prather RS: Development and apoptosis of pre-implantation porcine nuclear transfer embryos activated with different combination of chemicals. Mol Reprod Dev 2006, 73(9): 1094-|I0I.

26. Machaty Z, Wang WH, Day BN, Prather RS: Complete activation of porcine oocytes induced by the sulfhydryl reagent, thimerosal. Biol Reprod 1997, 57(5): I I23-I I 27.

27. Kishigami $\mathrm{S}$, Wakayama $\mathrm{T}$ : Efficient strontium-induced activation of mouse oocytes in standard culture media by chelating calcium. J Reprod Dev 2007, 53(6): | 207-1215.

28. Machaty Z, Ramsoondar IJ, Bonk AJ, Prather RS, Bondioli KR: $\mathrm{Na}^{+}$ $\mathrm{Ca}^{2+}$ exchanger in porcine oocytes. Biol Reprod 2002, 67(4): II33-1139.

29. Pope CE: In vitro fertilization and embryo transfer in felids. Methods Mol Biol 2004, 254:227-244.

30. Gomez MC, Pope CE, Dresser BL: Nuclear transfer in cats and its application. Theriogenology 2006, 66(I):72-8I.

31. Serpersu EH, Kinosita K Jr, Tsong TY: Reversible and irreversible modification of erythrocyte membrane permeability by electric field. Biochim Biophys Acta 1985, 8I 2(3):779-785.

32. Ilyin V, Parker I: Effects of alcohols on responses evoked by inositol trisphosphate in Xenopus oocytes. J Physiol 1992, 448:339-354.

33. Meo SC, Yamazaki W, Ferreira CR, Perecin F, Saraiva NZ, Leal CL, Garcia JM: Parthenogenetic activation of bovine oocytes using single and combined strontium, ionomycin and 6-dimethylaminopurine treatments. Zygote 2007, I5(4):295-306.

34. Lan GC, Han D, Wu YG, Han ZB, Ma SF, Liu XY, Chang CL, Tan JH: Effects of duration, concentration, and timing of ionomycin and 6-dimethylaminopurine (6-DMAP) treatment on activation of goat oocytes. Mol Reprod Dev 2005, 7 I (3):380-388.

35. Abramson JJ, Cronin JR, Salama G: Oxidation induced by phthalocyanine dyes causes rapid calcium release from sarcoplasmic reticulum vesicles. Arch Biochem Biophys 1988, 263(2):245-255.

36. Trimm JL, Salama G, Abramson JJ: Sulfhydryl oxidation induces rapid calcium release from sarcoplasmic reticulum vesicles. J Biol Chem 1986, 26 I(34): 16092-16098.

37. Fissore RA, Robl JM: Sperm, inositol trisphosphate, and thimerosal-induced intracellular $\mathrm{Ca}^{2+}$ elevations in rabbit eggs. Dev Biol 1993, 159(I): 122-130.

38. Sayers LG, Brown GR, Michell RH, Michelangeli F: The effects of thimerosal on calcium uptake and inositol 1,4,5-trisphosphate-induced calcium release in cerebellar microsomes. Biochem J 1993, 289(Pt 3):883-887.

39. Wakayama T, Perry AC, Zuccotti M, Johnson KR, Yanagimachi R: Full-term development of mice from enucleated oocytes injected with cumulus cell nuclei. Nature 1998, 394(669 I):369-374.

40. Whittingham DG, Siracusa G: The involvement of calcium in the activation of mammalian oocytes. Exp Cell Res 1978, II3(2):3II-3I7.

4I. Zhang D, Pan L, Yang LH, He XK, Huang XY, Sun FZ: Strontium promotes calcium oscillations in mouse meiotic oocytes and early embryos through InsP $_{3}$ receptors, and requires activation of phospholipase and the synergistic action of $\operatorname{Ins}_{3}$. Hum Reprod 2005, 20(II):3053-306I.

42. Nicoll DA, Longoni S, Philipson KD: Molecular cloning and functional expression of the cardiac sarcolemmal $\mathrm{Na}^{+}-\mathrm{Ca}^{2+}$ exchanger. Science 1990, 250(4980):562-565.

43. Igusa $Y$, Miyazaki S: Effects of altered extracellular and intracellular calcium concentration on hyperpolarizing responses of the hamster egg. J Physiol 1983, 340:61 I-632.

44. Carroll $\mathrm{J}: \mathrm{Na}^{+}-\mathrm{Ca}^{2+}$ exchange in mouse oocytes: modifications in the regulation of intracellular free $\mathrm{Ca}^{2+}$ during oocyte maturation. J Reprod Fertil 2000, I 18(2):337-342.

45. Pepperell JR, Kommineni K, Buradagunta S, Smith PJ, Keefe DL: Transmembrane regulation of intracellular calcium by a plasma membrane sodium/calcium exchanger in mouse ova. Biol Reprod 1999, 60(5): I I37-I I 43.

46. Kuriyama $\mathrm{R}$, Sakai $\mathrm{H}$ : Role of tubulin-SH groups in polymerization to microtubules. Functional-SH groups in tubulin for polymerization. J Biochem 1974, 76(3):65|-654.

47. Hashimoto $N$, Watanabe $N$, Furuta $Y$, Tamemoto $H$, Sagata $N$, Yokoyama M, Okazaki K, Nagayoshi M, Takeda N, lkawa Y, Aizawai 
S: Parthenogenetic activation of oocytes in c-mos-deficient mice. Nature 1994, 370(6484):68-7I.

48. Liu L, Ju JC, Yang X: Parthenogenetic development and protein patterns of newly matured bovine oocytes after chemical activation. Mol Reprod Dev 1998, 49(3):298-307.

49. O'Brien SJ, Menotti-Raymond M, Murphy WJ, Yuhki N: The Feline Genome Project. Annu Rev Genet 2002, 36:657-686.

50. Winchester B, Vellodi A, Young E: The molecular basis of lysosomal storage diseases and their treatment. Biochem Soc Trans 2000, 28(2): $150-154$

51. Swanson WF: Research in nondomestic species: experiences in reproductive physiology research for conservation of endangered felids. ILAR J 2003, 44(4):307-3I6.

52. Hao YH, Yong HY, Murphy CN, Wax D, Samuel M, Rieke A, Lai L, Liu Z, Durtschi DC, Welbern VR, Price EM, McAllister RM, Turk JR, Laughlin MH, Prather RS, Rucker EB: Production of endothelial nitric oxide synthase (eNOS) over-expressing piglets. Transgenic Res 2006, 15(6):739-750.

Publish with Bio Med Central and every scientist can read your work free of charge

"BioMed Central will be the most significant development for disseminating the results of biomedical research in our lifetime. "

Sir Paul Nurse, Cancer Research UK

Your research papers will be:

- available free of charge to the entire biomedical community

- peer reviewed and published immediately upon acceptance

- cited in PubMed and archived on PubMed Central

- yours - you keep the copyright

Submit your manuscript here:

http://www.biomedcentral.com/info/publishing_adv.asp
BiolMedcentral 